\title{
Courtship Song Genes and Speciation in Sand Flies
}

\author{
SG Oliveira*, M Bottecchia, LGSR Bauzer, NA Souza**, RD Ward***, \\ CP Kyriacou****, AA Peixoto/ ${ }^{+}$
}

\begin{abstract}
Departamento de Bioquímica e Biologia Molecular **Departamento de Entomologia, Instituto Oswaldo CruzFiocruz, Av. Brasil 4365, 21045-900 Rio de Janeiro, RJ, Brasil *Departamento de Biologia Animal e Vegetal, Universidade Estadual do Rio de Janeiro, Rio de Janeiro, Brasil ***The Centre for Applied Entomology and Parasitology, School of Life Sciences, University Keele, UK ****Department of Genetics, University of Leicester, Leicester, UK
\end{abstract}

Lutzomyia longipalpis (Lutz \& Neiva, 1912) (Diptera: Psychodidae: Phlebotominae) is a vector of visceral leishmaniasis in the Americas and it might represent a complex of sibling species. Reproductive isolation between closely related species often involves differences in courtship behaviour. cacophony (cac) and period (per) are two Drosophila genes that control features of the "lovesong" males produce during courtship that has been implicated in the sexual isolation between closely related species. We are using gene fragments from L. longipalpis' homologues of these two genes to study the speciation process in this putative species complex.

Key words: Lutzomyia longipalpis - cacophony - period - polymorphism

Genes controlling aspects of reproductive behaviour are among the best molecular markers in the study of speciation in insect vectors. In Drosophila, males vibrate their wings during courtship producing a kind of "lovesong". This acoustic signal is potentially involved in the reproductive isolation between closely related species (Kyriacou \& Hall 1982, 1986, Ritchie et al. 1999). Among the genes controlling this "lovesong" (Hall 1994), cacophony (cac) and period (per) are particularly interesting as they control features of the song that are known to vary between species (see below).

cac codes for a voltage-gated calcium channel $\alpha-1$ subunit, a large protein that forms the pore of the channel. cac is a very large (over $45 \mathrm{~kb}$ ) and complex gene that presents alternative splicing and RNA editing of its transcript (Smith et al. 1996, 1998a, b, Peixoto et al. 1997). It is also the site of song $\left(\right.$ cac $\left.^{S}\right)$, visual (night-blind-A) and lethal (L13) mutations. In vertebrates, voltage-gated calcium channels are divided in many different classes according to their electrophysiological characteristics, pharmacology, sequence similarities and tissue distribution (Stea et al. 1995). cac, also known as DmcalA, shows homology to vertebrate calcium

This work was supported by the Wellcome Trust with additional support from Faperj, Fiocruz and CNPq. ${ }^{+}$Corresponding author. Fax: +55-21-590.3495. E-mail: apeixoto@gene.dbbm.fiocruz.br

Received 13 November 2000

Accepted 3 January 2001 channel classes A, B and E. The song produced by its mutant allele $c a c$ is characterized by longer interpulse-intervals (IPIs) and pulses that contain more cycles than normal (Schilcher 1977, Kulkarni \& Hall 1987, Peixoto \& Hall 1998). These are two features that commonly show differences among various Drosophila species (e.g. Hoikkala \& Lumme 1987, Ritchie \& Gleason 1995).

The clock gene per controls a different feature of the "lovesong" of Drosophila. D. melanogaster and related species (Kyriacou \& Hall 1980, Demetriades et al. 1999) present cyclic variation in their mean IPI. These song rhythms are species-specific and they have been implicated as one of the signals females used to recognise conspecific males (Kyriacou \& Hall 1982, 1986, Ritchie et al. 1999). Because per controls the differences in song rhythms that seem to contribute to the reproductive isolation between $D$. melanogaster and its sibling species $D$. simulans (Wheeler et al. 1991), it has been called a "speciation gene" (Coyne 1992).

Acoustic communication is also a feature of the courtship behaviour of Lutzomyia longipalpis (Ward et al. 1988), a vector of visceral leishmaniasis in the Americas and a putative complex of sibling species (Ward et al. 1988, Lanzaro et al. 1993, Alexander et al. 1998, Uribe 1999). Using PCR with degenerated primers, we cloned and sequenced gene fragments from $L$. longipalpis' putative homologues of per and cac. In the case of per, the fragment is nearly $1 \mathrm{~Kb}$ long and includes a small intron ( $\sim 50 \mathrm{bp})$. It encodes the end of the PAS protein dimerisation domain and the Thr-Gly repeat region. The cac fragment is $\sim 270 \mathrm{bp}$ and 
encodes the IVS6 domain of the channel. It also includes an intron ( 100 bp). Based on these first sequences we designed more specific oligos for this species and we are now using them to study the molecular variation and differentiation among populations of the L. longipalpis complex in Brazil.

Figure shows the first results we obtained with the analysis of the IVS6 region of cac in the population of Natal (State of Rio Grande do Norte). Length variation was observed among PCR fragments amplified from different individuals. Sequencing of these fragments revealed a number of differences due to insertion/deletion events and point mutations within the intron in this region of L. longipalpis' cac (Figure). Preliminary analysis of a number of other sand flies from Natal and from the population of Lapinha (Lagoa Santa, State of Minas Gerais) confirms that this intron of $c a c$ is highly polymorphic and indicates that the two populations are quite differentiated. For example, the Table shows the frequencies of haplotypes associated with two major deletions found in this intron. Significant differences are observed between the populations of Natal and Lapinha $\left(X^{2}=10.26\right.$; d.f. $=2 ; p=0.0059)$. The haplotype associated with deletion 1 has a frequency of $36.4 \%(8 / 22)$ in Natal but has yet to be observed in Lapinha, while in this latter population the haplotype associated with deletion 2 is fairly common $(30 \% ; 6 / 20)$, although it was not found in Natal.

We also started the analysis of the molecular variation in a region of the per gene fragment of $L$. longipalpis in the populations of Lapinha and Jacobina (State of Bahia). The first results also in-
TABLE

cacophony haplotype frequencies in two populations of Lutzomyia longipalpis

\begin{tabular}{lcc}
\hline Haplotypes & Natal & Lapinha \\
\hline del I & $36.3 \%$ & - \\
del II & - & $30 \%$ \\
others & $63.7 \%$ & $70 \%$ \\
\hline Total & 22 & 20 \\
\hline
\end{tabular}

dicate that these two populations are quite differentiated. We sequenced a $266 \mathrm{bp}$ fragment in 35 individuals (17 of Lapinha and 18 of Jacobina). Of a total of 33 polymorphic sites found so far, only six are shared between the two populations. The calculated Fst for the data is 0.3911 (Hudson et al. 1992, Rozas \& Rozas 1999). This figure predicts only 0.39 migrants per generation $(\mathrm{Nm})$, a value nearly ten times smaller than the ones predicted by isoenzyme loci (Mukhopadhyay et al. 1998, Mutebi et al. 1999, Azevedo et al. 2000).

The differentiation between the Natal, Lapinha and Jacobina populations at the molecular level is supported by the first results obtained with the analysis of the "lovesongs" produced by $L$. longipalpis males from these very same populations (Souza \& Peixoto, unpublished), and raises the question of whether they represent different sibling species. Cryptic speciation is one of the most interesting phenomena in evolution and its occurrence in phlebotomine sand flies has important epidemiological consequences (Lanzaro \& Warburg 1995). The results obtained so far with

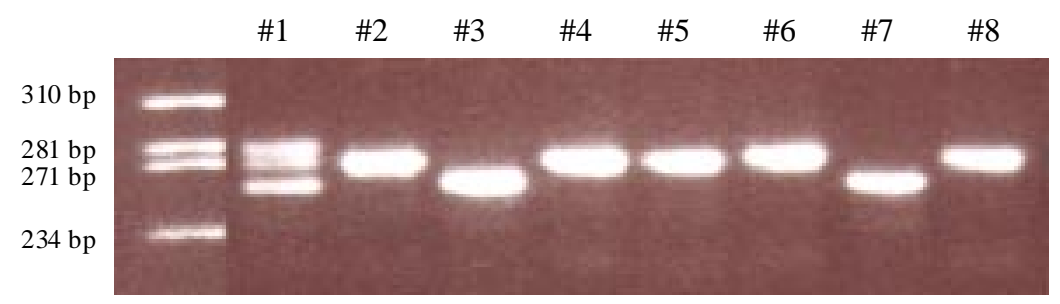

P N IMLACLKGRP CDERAGKEPHETCGSS LAYAYFVSF IFF C S L L L NLFVAV

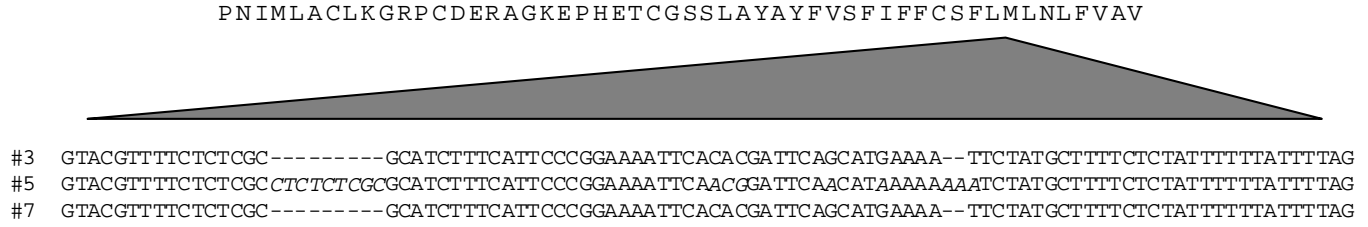

Length polymorphism in the IVS6 intron of cacophony in Lutzomyia longipalpis. Top: agarose gel (NuSieve) showing the length variation among PCR amplified fragments from different $L$. longipalpis males. Note that sand fly \#1 is heterozygous for two different length variants. Botton: amino acid sequence of the IVS6 region and intron sequences of some of the PCR fragments showed on top. 
the analysis of the molecular variation in $c a c$ and per suggest that courtship song genes will be very useful to enhance our knowledge of the speciation process in the L. longipalpis complex.

\section{ACKNOWLEDGEMENTS}

To Reginaldo Brazil (CPqRR, Belo Horizonte, Brazil), Iraci Duarte (FNS, Natal, Brazil) and Italo Sherlock (CPqGM, Salvador, Brazil) for helping us in obtaining sand fly samples. To Paulo Roberto de Amoretty and Robson Costa da Silva for their technical assistance.

\section{REFERENCES}

Alexander B, Mutebi J-P, Hearne D, Lanzaro GC, Ward RD, Hamilton JGC 1998. Current status of the $L$. longipalpis species complex. Mem Inst Oswaldo Cruz 93 (Supl. 2): 31-33.

Azevedo ACR, Monteiro FA, Cabello PH, Souza NA, Rosa-Freita MG, Rangel EF 2000. Studies on populations of Lutzomyia longipalpis (Lutz \& Neiva, 1912) (Diptera: Psychodidae: Phlebotominae) in Brazil. Mem Inst Oswaldo Cruz 95: 305-322.

Coyne JA 1992. Genetics and speciation. Nature 355: 511-515.

Demetriades MC, Thackeray JR, Kyriacou CP 1999. Courtship song rhythms in Drosophila yakuba. Anim Behav 57: 379-386.

Hall JC 1994. The mating of a fly. Science 264: 17021714.

Hoikkala A, Lumme J 1987. The genetic basis of evolution of the male courtship sounds in the Drosophila virilis group. Evolution 41: 827-845.

Hudson RR, Slatkin M, Maddison P 1992. Estimation of levels of gene flow from DNA sequence data. Genetics 132: 583-589.

Kulkarni SJ, Hall JC 1987. Behavioral and cytogenetic analysis of the cacophony courtship song mutant and interacting genetic variants in Drosophila melanogaster. Genetics 115: 461-475.

Kyriacou CP, Hall JC 1980. Circadian rhythm mutations in Drosophila affect short-term fluctuations in the male's courtship song. Proc Natl Acad Sci USA 77: 6929-6933.

Kyriacou CP, Hall JC 1982. The function of courtship song rhythms in Drosophila. Anim Behav 30: 784801.

Kyriacou CP, Hall JC 1986. Interspecific genetic control of courtship song production and reception in Drosophila. Science 232: 494-497.

Lanzaro GC, Warburg A 1995. Genetic variability in phlebotomine sandflies: possible implications for leishmaniasis epidemiology. Parasitol Today 11: 151-154.

Lanzaro GC, Ostrovska K, Herrero MV, Lawyer PG, Warburg A 1993. Lutzomyia longipalpis is a species complex: genetic divergence and interspecific hybrid sterility among three populations. Am J Trop Med Hyg 48: 839-847.

Mukhopadhyay J, Ghosh K, Rangel EF, Munstermann LE 1998. Genetic variability in biochemical charac- ters of Brazilian field populations of the Leishmania vector, Lutzomyia longipalpis (Diptera: Psychodidae). Am J Trop Med Hyg 59: 893-901.

Mutebi JP, Alexander B, Sherlock I, Wellington J, Souza AA, Shaw J, Rangel EF, Lanzaro GC 1999. Breeding structure of the sand fly Lutzomyia longipalpis (Lutz \& Neiva) in Brazil. Am J Trop Med Hyg 61: 149-157.

Peixoto AA, Hall JC 1998. Analysis of temperature-sensitive mutants reveals new genes involved in the courtship song of Drosophila. Genetics 148: 827838.

Peixoto AA, Smith LA, Hall JC 1997. Genomic organization and evolution of alternative exons in a Drosophila calcium channel gene. Genetics 145: 10031013.

Ritchie MG, Gleason JM 1995. Rapid evolution of courtship song pattern in Drosophila willistoni sibling species. J Evol Biol 8: 463-479.

Ritchie MG, Halsey EJ, Jennifer M, Gleason JM 1999. Drosophila song as a species-specific mating signal and the behavioural importance of Kyriacou \& Hall cycles in D. melanogaster song. Anim Behav 58: 649657.

Rozas J, Rozas R 1999. DnaSP version 3: an integrated program for molecular population genetics and molecular analysis. Bioinformatics 15: 174-175.

Schilcher Fv 1977. A mutant which changes courtship song in Drosophila melanogaster. Behav Genet 7: 251-259.

Smith LA, Peixoto AA, Hall JC 1998b. RNA editing in the Drosophila DMCA1A calcium-channel $\alpha-1$ subunit transcript. J Neurogenetics 12: 227-240.

Smith LA, Peixoto AA, Kramer EM, Villella A, Hall JC 1998a. Courtship and visual defects of cacophony mutants reveal functional complexity of a calciumchannel $\alpha-1$ subunit in Drosophila. Genetics 149: 1407-1426.

Smith LA, Wang XJ, Peixoto AA, Neumann EK, Hall LM, Hall JC 1996. A Drosophila calcium channel $\alpha-1$ subunit gene maps to a genetic locus associated with behavioral and visual defects. J Neuroscience 16: 7868-7879.

Stea A, Soong TW, Snutch TP 1995. Voltage-gated calcium channels. In RA North, Ligand- and Voltage-gated Ion Channels, CRC Press, Inc., Boca Raton, p. 114-151.

Uribe S 1999. The status of the Lutzomyia longipalpis species complex and possible implications for Leishmania transmission. Mem Inst Oswaldo Cruz 94: 729-734.

Ward RD, Phillips A, Burnet B, Marcondes CB 1988. The Lutzomyia longipalpis complex: reproduction and distribution. In MW Service, Biosystematics of Haematophagous Insects, Oxford University Press, Oxford, p. 258-269.

Wheeler DA, Kyriacou CP, Greenacre ML, Yu Q, Rutila JE, Rosbash M, Hall JC 1991. Molecular transfer of a species-specific behavior from Drosophila simulans to Drosophila melanogaster. Science 251: 1082-1085. 
Courtship Song Genes in L. longipalpis - SG Oliveira et al. 